\title{
Medical Equipment Logistics Capability Evaluation of third-party Logistics Service Providers
}

\author{
Zijuan Zhang \\ School of Economics and Management \\ Beijing Jiaotong University \\ P.R. China, 100044
}

\author{
Xianliang Shi \\ School of Economics and Management \\ Beijing Jiaotong University \\ P.R. China, 100044
}

\begin{abstract}
Medical equipment third-party logistics service has positive significance to standardized, intensive management for storage and transportation processes, evaluation of logistics capability is the first premise for product manufacturer or operator to select providers. According to the characteristics of the medical equipment third-party logistics, and based on the actual research, this paper proposed an evaluation model, and selected 13 indicators from four aspects in basic resources, business operation, monitoring management and human resources to build evaluation index system. With grey correlation ideal scheme decision method, this paper used the distance of grey correlation degree between third-party logistics service providers and the ideal point to replace gap with the industry benchmark, and evaluated logistics capability according to the size of grey correlation degree. This paper selected data of $\mathbf{1 0}$ enterprises carrying out medical equipment third-party logistics service, with the evaluation system and grey correlation ideal scheme decision method to take the empirical analysis, finally concluded the pecking order of enterprise logistics service capability, and given improving guidance to providers in medical equipment third-party logistics ability, which is of great significance to sustainable development for the third-party logistics service of medical equipment.
\end{abstract}

Keywords-medical equipment; third-party logistics; logistics capability evaluation;grey correlation degree

\section{INTRODUCTION}

Medical equipment, the instruments, materials and other goods directly or indirectly in human body, based on disease prevention, diagnosis, treatment and so on purpose, to protect public health and life security, plays an important role on improving quality of life. At present, Medical equipment logistics has many insufficient standard phenomena, and it's hard to ensure product quality safe and effective in storage and transportation. The 2014 revision of the measures for the supervision and administration of medical devices management increased three regulations to the provision of medical apparatus and instruments of third party logistics, for the first time on the law level of the legal status for third-party logistics enterprises to build a solid platform. Medical equipment third-party logistics service has positive significance to its storage and transport business processes of standardized, intensive management, and meets the needs of the industry development.
Logistics capability evaluation of logistics service providers is the first premise of medical equipment product manufacturer or operator to select third-party logistics service providers. In recent years, domestic and foreign scholars try to study logistics capability from different angles. From the aspects of the definition of logistics capability, Donald[1] think logistics capability is under the condition of the lowest total cost of the enterprise, providing a competitive advantage of a relative assessment of the logistics service capability; From the aspects of logistics capability factors, HUNG, Shihua $\mathrm{Ma}$ [2-3] earlier researched the composition of logistics capability in their paper, according to the nature of the logistics service capability elements of logistics service capability system mainly by the factors of time efficiency, information elements, customer three elements, and research has extended to supply chain level, and Lynch[4-5] divided the logistics capability into business operation ability such as additional value-added service ability of 22 parts, and put forward the importance of logistics capability and enterprise strategic match; From the aspects of logistics operation, Fawcett[6] emphasis on ability and value added potential ability based on time, and with the cost, quality, delivery, flexible and innovative five indicators, and evaluation of logistics capability system is established.

By analyzing the logistics capability related literature, the domestic and foreign experts and scholars in the definition of logistics capability, logistics capability factors and logistics operation has done a lot of work. On the macro has formed a fairly complete theoretical system of logistics capability, but the third-party logistics of medical devices is a specific industry, how to evaluate medical equipment third-party logistics ability also rare attention. Based on this, according to the characteristics of the medical equipment the third-party logistics development reality, combined investigation with 10 medical enterprises of third-party logistics service in Beijing, this paper would establish a system of logistics capability evaluation, and put forward a evaluation model about the medical equipment of third-party logistics service provider, in basic resources, business operation, monitoring management and human resources four aspects to select 13 indicators for building third-party logistics service providers capability evaluation index system.

Using appropriate theoretical method for medical equipment evaluation decision is necessary for the third-party logistics service provider of logistics capability evaluation. At 
present, method to evaluate logistics capability research mainly include the analytic hierarchy process (AHP), technique for order preference by similarity to ideal solution (TOPSIS ), the GM model of gray system theory, factor analysis and regression analysis method, etc. Min Li and Tao Zhao[7] use analytic hierarchy process (AHP) as the tool, and establish logistics service providers selection decision model. Bottani $\mathrm{E}[8]$ adopts the TOPSIS method to complete the selection and evaluation of the third-party reverse logistics enterprises model design and implementation. Tai Zhou[9] uses the grey system GM model combined with radial basis function (RBF) neural network, to predict the logistics capability. Guangsheng Zhang[10] has done logistics capability evaluation research in China according to the characteristics of the logistics industry development based on grey relation projection model. Shiping Cheng[11] uses factor analysis method, and studies the logistics capability evaluation index. Xiaoli Wang[12] proposes a decision making method, combined with ideal solution method, grey correlation model of grey correlation degree with each scheme and ideal scheme to replace the distance between each scheme and ideal scheme, for quantitative analysis of the logistics capability.

Through the analysis of the literature of logistics capability evaluation related theory method, grey correlation decisionmaking is one of the most commonly used decision method, and has the advantages of simple, practical and the operability is strong. So this paper adopts a method of grey correlation decision-making of ideal point, combined with ideal point method. The medical instrument of grey correlation degree of third-party logistics service providers with ideal point replaces the distance between the industry benchmark, according to the size of grey correlation degree to evaluate logistics capability. Lastly, 10 medical equipment enterprises' data of the thirdparty logistics service providers carry out. According to evaluation system building and the empirical analysis using grey correlation decision-making of ideal point method, it is concluded that the enterprise logistics service capability of the pecking order, and the improving guidance is put forward.

\section{BUILDING EVALUATION INDEX SYSTEM}

To build the index system of logistics capability is the necessary premise of medical equipment third-party logistics service providers. Different industry of third-party logistics service select indexes of different emphasis, and each industry of third-party logistics services are restricted by many factors. In most cases, third-party logistics service provider of logistics capability evaluation is the basic resources strength, business operations, and ancillary services as the evaluation index system of core dimensions. In this paper, on the basis of combining the characteristics of the medical equipment industry and enterprise application process, we introduced the monitoring traceability management ability as an important indicator.

Medical equipment third-party logistics has high threshold and high risk, and there are stricter requirements to the logistics service providers. Engaged in medical equipment in the third-party logistics not only need infrastructure equipment resources and strong operational capacity, but also need more perfect monitoring management ability, especially the quality control and circulation of retrospective. In addition, professional logistics personnel are also an important factor affecting medical devices of third-party logistics service providers' logistics capability. Based on these characteristics, this paper proposed an evaluation model about medical equipment of third-party logistics service provider (as shown in Figure 1).

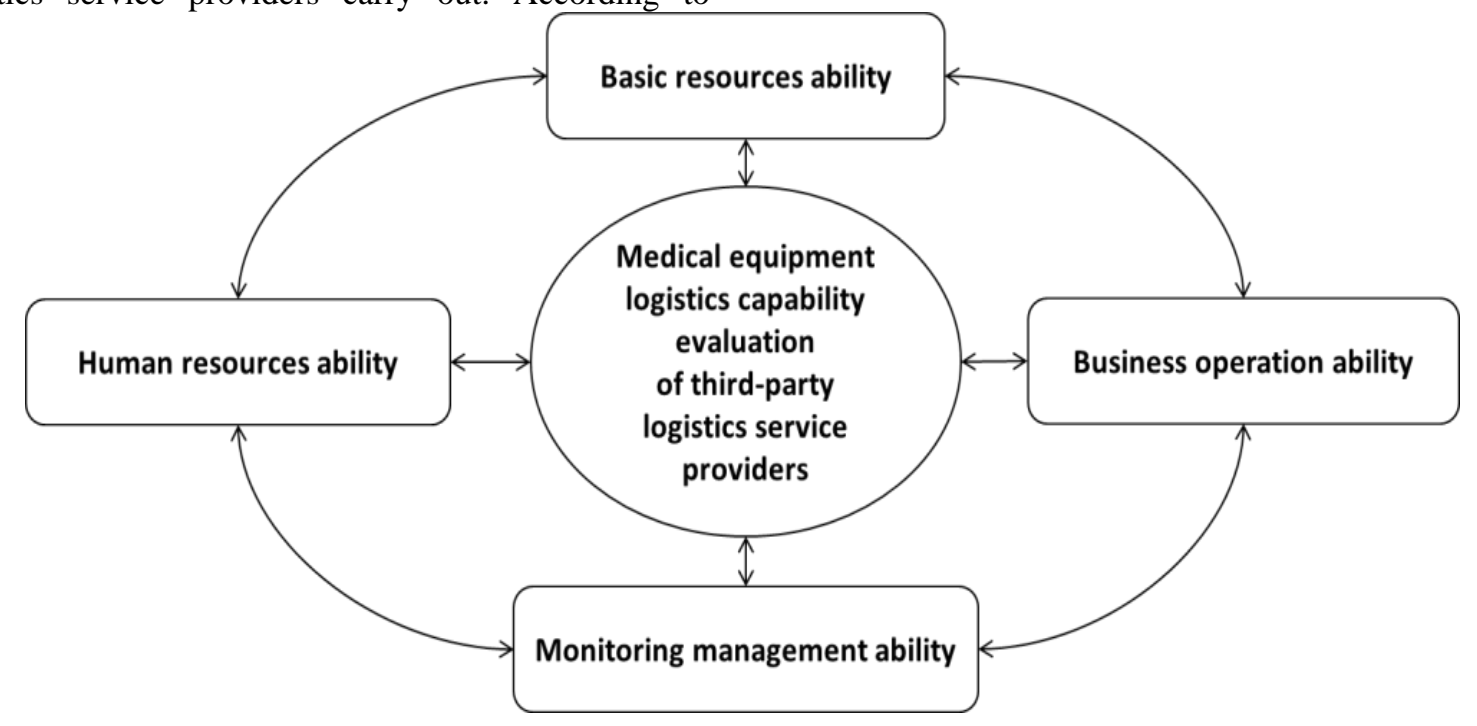

FIGURE I. MEDICAL EQUIPMENT THIRD-PARTY LOGISTICS SERVICE PROVIDER EVALUATION MODEL

Comprehensively thinking the above four aspects, this paper constructs evaluation index system of the medical appliances third-party logistics service provider in logistics capability, provides the basis of selection and evaluation for the medical device operation enterprises to choose the third- party logistics service provider. Considering the representative data, availability and reliability, we selected 13 indicators in basic resources, business operation, monitoring, management and human resources four aspects to build medical equipment 
of third-party logistics service providers' logistics capability

evaluation index system(See table 1).

TABLE I. EVALUATION INDEX SYSTEM OF MEDICAL EQUIPMENT THIRD-PARTY LOGISTICS CAPABILITY

\begin{tabular}{|c|c|c|c|c|}
\hline The target layer & Level 1 indicators & Level 2 indicators & Level 3 indicators & Index type \\
\hline \multirow{13}{*}{$\begin{array}{l}\text { Medical equipment } \\
\text { logistics capability } \\
\text { evaluation of third- } \\
\text { party logistics service } \\
\text { providers }\end{array}$} & \multirow{4}{*}{ Basic resources } & \multirow{2}{*}{$\begin{array}{l}\text { Storage and } \\
\text { transportation facilities }\end{array}$} & Warehousing facilities(X1) & Cost target \\
\hline & & & Transportation facilities(X2) & Cost target \\
\hline & & \multirow{2}{*}{$\begin{array}{l}\text { Information equipment } \\
\text { capacity }\end{array}$} & Basic software and hardware facilities(X3) & Cost target \\
\hline & & & $\begin{array}{l}\text { Storage transportation and tracing information } \\
\text { system }(\mathrm{X} 4)\end{array}$ & Cost target \\
\hline & \multirow{4}{*}{ Business operation } & \multirow{2}{*}{$\begin{array}{l}\text { Proprietary trading } \\
\text { operating ability }\end{array}$} & Proprietary trading throughput(X5) & Benefits target \\
\hline & & & Proprietary trading turnover(X6) & Benefits target \\
\hline & & \multirow{2}{*}{$\begin{array}{l}\text { Entrusted trading } \\
\text { operating capacity }\end{array}$} & Entrusted trading throughput(X7) & Benefits target \\
\hline & & & Entrusted trading turnover(X8) & Benefits target \\
\hline & \multirow{3}{*}{$\begin{array}{l}\text { Monitoring } \\
\text { management }\end{array}$} & \multirow{2}{*}{$\begin{array}{l}\text { Quality control } \\
\text { management ability }\end{array}$} & The security of storage quality(X9) & Benefits target \\
\hline & & & The security of transportation quality (X10) & Benefits target \\
\hline & & $\begin{array}{l}\text { Flow tracing } \\
\text { management ability }\end{array}$ & The RF information collection and utilization (X11) & Benefits target \\
\hline & \multirow{2}{*}{ Human resources } & \multirow{2}{*}{$\begin{array}{l}\text { Personnel resource } \\
\text { support capability }\end{array}$} & Storage and transportation personnel number (X12) & Benefits target \\
\hline & & & Logistics management personnel number (X13) & Benefits target \\
\hline
\end{tabular}

\section{GREY CORRELATION IDEAL SCHEME DECISION METHOD}

\section{A. Grey Correlation Model}

The basic task of the grey correlation analysis is based on the behavior of micro or macro factor sequence geometrical close, to analyze and confirm the influence degree between factors or to measure the contribution of the main behavior.

Gray correlation degree model has a wide range of application, in the dynamic process analysis, trend prediction, investment choice; evaluation is applied in decision making.

Set up the system behavior sequence:

$X_{0}=\left\{x_{0}(1), x_{0}(2), \cdots, x_{0}(n)\right\}$,

$X_{i}=\left\{x_{i}(1), x_{i}(2), \cdots, x_{i}(n)\right\}, i=1,2, \cdots, m$,

And make

$$
\begin{aligned}
& \left|S_{0}\right|=\sum_{k=1}^{n}\left|x_{0}(k)\right| \quad, \quad\left|S_{i}\right|=\sum_{k=1}^{n}\left|x_{i}(k)\right|, \\
& \left|S_{0}-S_{i}\right|=\sum_{k=1}^{n}\left|x_{0}(k)-x_{i}(k)\right|,
\end{aligned}
$$$$
\text { So } \quad \text { call } \quad \varepsilon_{0 i}=\frac{1+\left|S_{0}\right|+\left|S_{i}\right|}{1+\left|S_{0}\right|+\left|S_{i}\right|+\left|S_{0}-S_{i}\right|} \quad \text { as grey }
$$

correlation for sequence $X_{0}$ and $X_{i}$

Medical equipment of third-party logistics service provider's logistics capability evaluation belongs to the medical device manufacturers or operators selection or evaluation problem of third-party logistics service providers. Combined with the principle of grey correlation model and scope of application, it proves that this method is applicable to research the problem.

\section{B. Grey Correlation Ideal Scheme Decision-Making Process}

Grey relational decision making method of thought is the solution to the distance between the ideal scheme using the grey correlation degree between each scheme and ideal scheme, and then according to each scheme and ideal scheme of the size of the grey correlation degree to give a ranking .

Specific decision-making process is as follows:

Set a scheme for evaluation $S=\left\{S_{1}, S_{2}, \cdots, S_{m}\right\}$.The properties of each scheme are $X=\left\{X_{1}, X_{2}, \cdots, X_{n}\right\}$, scheme $S_{i}$ with property $X_{j}$ the attribute value is $a_{i j}$, for attribute decision matrix is $A=\left(a_{i j}\right)_{m n}$.

Step 1 Standardized the attribute decision matrix A

Set $a_{j}{ }^{\max }$ as the maximum of attribute $j, a_{j}{ }^{\min }$ as the minimum.

When $X_{j}$ belongs to quality-benefit attributes type:

$$
\text { Set } b_{i j}=\frac{a_{i j}-a_{j}{ }^{\min }}{a_{j}{ }^{\max }-a_{j}{ }^{\min }}, i=1,2, \cdots, m, j=1,2, \cdots, n \text {; }
$$


When $X_{j}$ belongs to cost-benefit attributes type:

Set $b_{i j}=\frac{a_{j}{ }^{\max }-a_{i j}}{a_{j}{ }^{\max }-a_{j}{ }^{\min }}, i=1,2, \cdots, m, j=1,2, \cdots, n$;

So standardize the attribute decision matrix to $B=\left(b_{i j}\right)_{m n}$.

Step 2 Determine the ideal point

There will be one of the elements in each property after normalized to 1 , so the ideal point is $S_{0}=\{1,1, \cdots, 1\}$.

Step 3 Use the grey correlation model in the theorem 1,correlation of each scheme to the ideal point is $\varepsilon_{0 i}=\frac{1+\left|S_{0}\right|+\left|S_{i}\right|}{1+\left|S_{0}\right|+\left|S_{i}\right|+\left|S_{0}-S_{i}\right|} \quad i=1,2, \cdots, m$.

Step 4 Based on $\varepsilon_{0 i}, i=1,2, \cdots, m$, and then we get the size of scheme for sorting.

According to the proposed medical appliances third-party logistics service provider of logistics capability evaluation model and index evaluation system, it is easy to ideal scheme decision-making process based on grey correlation evaluation, and it has a strong operability. So, according to the characteristics and the practical maneuverability, grey correlation ideal scheme decision-making models show the applicability.

\section{THE EMPIRICAL ANALYSIS}

According to the medical equipment third-party logistics service provider evaluation index system of logistics capability in table 1, this paper use 10 medical enterprises' data in Beijing, from 13 basic indicators of third-party logistics service capability (as shown in table 2) on medical apparatus and instruments for quantitative evaluation..

Step 1 According to the statistics in table 2, establish attribute decision matrix, carry on the standardization attribute decision matrix, and then get the normalized data matrix, as shown in table 3.

TABLE II. 10 MEDICAL EQUIPMENT THIRD-PARTY ENTERPRISES’ LOGISTICS CAPABILITY INDEX DATA IN BEIJING

\begin{tabular}{|c|c|c|c|c|c|c|c|c|c|c|c|c|c|}
\hline No. & $\mathrm{X} 1$ & $\mathrm{X} 2$ & X3 & $\mathrm{X} 4$ & $\mathrm{X5}$ & X6 & $\mathrm{X7}$ & $\mathrm{X8}$ & X9 & $\mathrm{X} 10$ & X11 & $\mathrm{X} 12$ & $\mathrm{X} 13$ \\
\hline 1 & 28174.2 & 66 & 1 & 3 & 440000 & 37881.2 & 0 & 0 & $100 \%$ & $100 \%$ & 1 & 96 & 4 \\
\hline 2 & 39159 & 19 & 0.5 & 1.5 & 858011 & 45350 & 570 & 1800 & $99 \%$ & $99.30 \%$ & 0.5 & 96 & 13 \\
\hline 3 & 22806 & 3 & 0.5 & 1.5 & 3000000 & 158000 & 150000 & 700 & $100 \%$ & $100 \%$ & 1 & 47 & 6 \\
\hline 4 & 27564 & 10 & 1 & 2.5 & 2830000 & 30308.6 & 0 & 0 & $99.95 \%$ & $99.93 \%$ & 0.5 & 31 & 2 \\
\hline 5 & 17200 & 3 & 0.5 & 0 & 495498 & 221100 & 300000 & 1500 & $100 \%$ & $100 \%$ & 1 & 20 & 2 \\
\hline 6 & 10942.24 & 8 & 1 & 0.5 & 1000 & 228 & 50 & 85 & $100 \%$ & $100 \%$ & 1 & 21 & 2 \\
\hline 7 & 35000 & 10 & 0.5 & 1.5 & 396000 & 25000 & 0 & 0 & $99.5 \%$ & $100 \%$ & 0 & 49 & 15 \\
\hline 8 & 16524 & 0 & 0.5 & 1 & 20000 & 25000 & 800 & 200 & $99 \%$ & $99.30 \%$ & 1 & 21 & 2 \\
\hline 9 & 25592 & 2 & 0.5 & 1 & 4927 & 576 & 0 & 0 & $100 \%$ & $100 \%$ & 1 & 31 & 2 \\
\hline 10 & 41580 & 15 & 0.5 & 1.5 & 22000 & 9333 & 60000 & 30000 & $99.995 \%$ & $99.993 \%$ & 0.5 & 89 & 2 \\
\hline
\end{tabular}

TABLE III. NORMALIZED DATA MATRIX OF 10 MEDICAL EQUIPMENT THIRD-PARTY ENTERPRISES

\begin{tabular}{|c|c|c|c|c|c|c|c|c|c|c|c|c|c|}
\hline No. & $\mathrm{X} 1$ & $\mathrm{X} 2$ & X3 & $\mathrm{X} 4$ & $\mathrm{X} 5$ & $\mathrm{X6}$ & $\mathbf{X 7}$ & $\mathbf{X 8}$ & X9 & $\mathrm{X} 10$ & X11 & $\mathrm{X} 12$ & $\mathrm{X} 13$ \\
\hline 1 & 0.438 & 0 & 0 & 0 & 0.146 & 0.170 & 0 & 0 & 1 & 1 & 1 & 1 & 0.154 \\
\hline 2 & 0.079 & 0.712 & 1 & 0.5 & 0.286 & 0.204 & 0.0019 & 0.06 & 0 & 0 & 0.5 & 1 & 0.846 \\
\hline 3 & 0.613 & 0.955 & 1 & 0.5 & 1 & 0.714 & 0.5 & 0.023 & 1 & 1 & 1 & 0.355 & 0.308 \\
\hline 4 & 0.457 & 0.848 & 0 & 0.167 & 0.943 & 0.136 & 0 & 0 & 0.95 & 0.9 & 0.5 & 0.145 & 0 \\
\hline 5 & 0.796 & 0.955 & 1 & 1 & 0.165 & 1 & 1 & 0.05 & 1 & 1 & 1 & 0 & 0 \\
\hline 6 & 1 & 0.879 & 0 & 0.833 & 0 & 0 & 0.000 & 0.003 & 1 & 1 & 1 & 0.013 & 0 \\
\hline 7 & 0.215 & 0.848 & 1 & 0.5 & 0.13171057 & 0.112 & 0 & 0 & 0.5 & 1 & 0 & 0.382 & 1 \\
\hline 8 & 0.818 & 1 & 1 & 0.667 & 0.006 & 0.112 & 0.003 & 0.007 & 0 & 0 & 1 & 0.013 & 0 \\
\hline 9 & 0.522 & 0.970 & 1 & 0.667 & 0.001 & 0.002 & 0 & 0 & 1 & 1 & 1 & 0.145 & 0 \\
\hline 10 & 0 & 0.773 & 1 & 0.5 & 0.007 & 0.041 & 0.2 & 1 & 0.995 & 0.99 & 0.5 & 0.908 & 0 \\
\hline
\end{tabular}


Step 2 The ideal point is $S_{0}=\{1,1, \cdots, 1\}$.

Step 3 Calculate the grey correlation degree every solution to the ideal point, the standardization of sequence is $S_{i}$ (data are shown in table 3), formula grey correlation degree of $S_{0}$ with ideal point through $\varepsilon_{0 i}=\frac{1+\left|S_{0}\right|+\left|S_{i}\right|}{1+\left|S_{0}\right|+\left|S_{i}\right|+\left|S_{0}-S_{i}\right|}$. The results are as follows:

$$
\begin{aligned}
& \varepsilon_{01}=0.705699035, \varepsilon_{02}=0.711233671, \varepsilon_{03}=0.791011553, \\
& \varepsilon_{04}=0.708429466, \varepsilon_{05}=0.790945479, \varepsilon_{06}=0.721870979, \\
& \varepsilon_{07}=0.721087599, \varepsilon_{08}=0.700119857, \varepsilon_{09}=0.733376973, \\
& \varepsilon_{010}=0.745720775 .
\end{aligned}
$$

Step 4 the solution of grey correlation degree to the ideal point shows that the 10 medical equipment logistics capabilities of the third-party logistics service providers from strong to weak order as follows:

$$
\text { (3) }>\text { (5) }>\text { (10) }>\text { (9) }>\text { (6) }>\text { (7) }>\text { (2) }>\text { (4) }>\text { (1) }>\text { (8) . }
$$

We found this 10 medical equipment providers of thirdparty logistics service logistics capability and all the indexes in the size of grey correlation degree between the ideal point of benchmarking is above 0.7, but presents the characteristics of uneven size, showing that the 10 companies of medical equipment third-party logistics service capability development is not balanced.

\section{CONCLUSION}

The paper through analyzing the characteristics of the medical equipment third-party logistics services in the first, and through the actual investigation, proposed an evaluation model about medical equipment of third-party logistics service provider. From the basic resources, business operation, monitoring management and human resources four aspects to screen the 13 indicators to build the evaluation index system of logistics capability, there are quantitative measurements for third-party logistics service provider of medical equipment, and the selection of indicators have comprehensive and representative. And then through the grey correlation degree distance between the ideal solution instead of gap between each scheme and ideal scheme, grey correlation ideal scheme decision method is established. This paper uses 10 medical enterprises' original statistical data corresponding indexes, through grey correlation ideal scheme decision method, and then from strong logistics ability to weak is concluded. The guidance for medical equipment logistics capability to improve is given.

Medical equipment third-party logistics service provider of logistics ability is uneven, and industry logistics capability presents unbalanced development situation. In order to improve equipment of third-party logistics industry logistics capability as a whole, we must set off from the global, carrying on the overall planning, effectively integrate the third-party logistics resources, establish medical appliances third-party logistics information sharing and collaboration platform, promote medical equipment of third-party logistics service enterprise comprehensive competitiveness, and then realize medical instrument sustained, healthy development of third-party logistics. Of course, the research method and process of third-party logistics service providers this paper adopts also applies to other industry logistics capability of quantitative evaluation, for the benign development of the third-party logistics to provide important reference basis.

\section{ACKNOWLEDGMENT}

This work is supported by Natural Science Foundation of China (Grant No.713900334), "EC-China Research Network on Integrated Container Supply Chain” Project (Project No.612546).

\section{REFERENCES}

[1] Bowersox D.J, Closs D.J. Logistics management: the integrated supply chain process[M].Lin Guolong, transl, Beijing: China Machine Press, 1998:1-30.

[2] KEEHUNG LAI. Service Capability and Performance of Logistics Service Providers [J] .Transportation Research Part E, 2004,40( 1) : 385-399.

[3] Shihua Ma, Tiewei Chen. Based on supply chain logistics service capability, components and evaluation method of research $[\mathrm{J}]$. Computer integrated manufacturing system,2007,13( 4) : 74750.

[4] Global Logistics Research Team of Michigan State University . World-class logistics: the challenge of managing continuous change[J].IIE Solution, 1995, 27(12):9.

[5] Lynch D.F, Keller S.B, Ozment J. the effects of logistics capabilities and strategy on firm performance [J].Journal of Business Logistics, 2000, 21(2): 47-69.

[6] Fawcett S.E, Stanley L.L, Smith S.R. Developing a logistics capability to improve the performance of international operations[J]. Journal of Business Logistics, 1997, 18(2):101-127.

[7] Min Li, Tao Zhao. The choice of the third party reverse logistics provider [J]. Journal of northwest agriculture and forestry university of science and technology (social science edition), 2006, 04:73- 77.

[8] Bottani E, Rizzi A.A fuzzy TOPSIS methodology to support outsourcing of logistics services [ J ] .Supply Chain Management,2006,11(4): 294-308.

[9] Tai Zhou. Regional logistics capability based on the grey radial basis function network combination forecast [J]. Highway traffic science and technology, 2010, 01: 149- 154.

[10] Guangsheng Zhang. Logistics capability evaluation research Based on the grey relation projection model [J]. Journal of Beijing Jiaotong University (social science edition), 2014, 02: 15- 19.

[11] Shiping Cheng. Logistics capability evaluation index based on factor analysis research[J]. Modern business, 2008,11: 131- 132.

[12] Xiaoli Wang. Regional logistics capability evaluation of the project decision-making based on grey relational ideal [J]. Statistics and decision, 2013, 16: 42- 44. 